\title{
24-hour intraocular pressure in glaucoma patients randomized to receive dorzolamide or brinzolamide in combination with latanoprost
}

This article was published in the following Dove Press journal:

Clinical Ophthalmology

30 June 2009

Number of times this article has been viewed

\section{Yoshimi Nakamura \\ Shusaku Ishikawa \\ Yuko Nakamura \\ Hiroshi Sakai \\ Ichiko Henzan \\ Shoichi Sawaguchi}

Department of Ophthalmology, University of the Ryukyus Faculty of Medicine, Okinawa, Japan
Correspondence: Shoichi Sawaguchi Department of Ophthalmology, University of the Ryukyus Faculty of Medicine, 207 Uehara, Nishihara, Okinawa 903-0215, Japan Tel $+8 \mid 98895$ II 80 $\mathrm{Fax}+8|98895| 427$ Email sshoichi@med.u-ryukyu.ac.jp
Purpose: To investigate the efficacy of dorzolamide 1\% (bid or tid) or brinzolamide 1\% bid on 24-hour intraocular pressure (IOP) control as well as patients' preference for either drug when added in combination with latanoprost against glaucoma (IOP, $\geq 18 \mathrm{mmHg}$ ).

Methods: In this randomized crossover study patients were assigned to receive latanoprost plus either dorzolamide or brinzolamide for four weeks. Thereafter, patients underwent 24-hour IOP monitoring while continuing to receive dorzolamide (for two successive days/nights: at first bid then tid) or brinzolamide bid (once overnight). They were then switched over to receive the other test medication for a further four weeks and subsequently reexamined for 24-hour IOP. A questionnaire survey on treatment satisfaction was performed.

Results: In 20 patients dorzolamide bid or tid or brinzolamide bid exerted significant $(p<0.001)$ reductions of IOP from baseline at all time-points over 24 hours; no difference was detected among the treatment regimens. Significantly $(p<0.05)$ more patients preferred dorzolamide $(\mathrm{n}=9)$ over brinzolamide $(\mathrm{n}=2)$, whereas nine patients gave a neutral answer.

Conclusion: Dorzolamide bid or tid and brinzolamide bid when combined with latanoprost therapy elicited significant IOP reduction for 24 hours. It is rational to consider patients' preference of therapeutic regimen especially long-term users such as those with glaucoma.

Keywords: glaucoma, brinzolamide, dorzolamide, latanoprost combination therapy, 24-hour intraocular pressure (IOP), questionnaire survey

\section{Introduction}

In the management of glaucoma, reduction of intraocular pressure (IOP) is the best and only evidence-based treatment modality; pharmacologic as well as surgical interventions aimed at reducing IOP may successfully slow the progression of structural damage and visual field loss in patients with the disease. ${ }^{1-4}$ Both the Advanced Glaucoma Intervention Study ${ }^{3}$ and Collaborative Initial Glaucoma Treatment Study ${ }^{4}$ have shown that IOP reduction should be achieved more aggressively than previously thought.

According to the Guidelines on Glaucoma Management in Japan, ${ }^{5}$ when pharmacologic IOP control is insufficient the first-line drug should be switched or combined with other medications. Accordingly, many glaucoma patients require polypharmacy for adequate IOP control during the life-long course of the disease. ${ }^{6,7}$ For this purpose, significant advances in the development of topical glaucoma medications have been achieved.$^{8-10}$ In recent years, prostaglandin analogs have gained popularity as first-line drugs for monotherapy; latanoprost for example effectively reduces IOP by increasing aqueous flow through the uveoscleral pathway. ${ }^{11-14}$ For combination 
therapy with a prostaglandin analog, add-on $\beta$-blocker has been extensively used and is probably the most common combination. ${ }^{15,16}$ Recently, however, the combined approach with latanoprost plus a topical carbonic anhydrase inhibitor (CAI) such as dorzolamide or brinzolamide has been demonstrated to lower IOP at least as effectively as that with additional $\beta$-blocker. ${ }^{17-19}$ This option of latanoprost plus CAI may also confer not only better nighttime IOP reduction than $\beta$-blocker, ${ }^{20}$ but also excellent systemic safety profiles. ${ }^{9,19}$

Although thrice-daily dosing of dorzolamide is officially approved in Japan, there is little information comparing the IOP-lowering efficacy of this dosing regimen versus that of twice-daily medication in Japanese patients. The present randomized, prospective study was designed to evaluate 24-hour control of IOP using dorzolamide $1 \%$ bid or tid in comparison with the standard CAI treatment in Japan, brinzolamide $1 \%$ bid, given in combination with latanoprost in Japanese patients with glaucoma. Also assessed was the patients' preference for either drug.

\section{Patients and methods}

\section{Patients}

Male and female glaucoma patients aged $\geq 20$ years whose IOP as ascertained by applanation tonometry (duplicate measurement) was $\geq 18 \mathrm{mmHg}$ despite receving monotherapy with latanoprost $0.005 \%$ once daily for $\geq 4$ weeks were enrolled. Inclusion criteria were primary open-angle glaucoma (POAG) defined as glaucomatous optic neuropathy with repeatable reliable visual field defect demonstrated by automated visual field perimetry, ocular hypertension $(\mathrm{OH})$ defined as IOP $>21 \mathrm{mmHg}$ without visual field loss, or post-laser iridotomy (LI) angle-closure glaucoma (ACG) defined as gonioscopically occludable angles with peripheral anterior synechia (PAS) formation and coexisting glaucomatous neuropathy and visual field loss. Patients with history of chronic or recurrent inflammatory eye disease, ocular trauma, or ocular infection within the past three months, corneal abnormality preventing reliable applanation tonometry, those undergoing intraocular surgery or currently using any ophthalmic, dermatologic, or systemic corticosteroid, oral CAIs, or sulfonamide drugs, and those with history of severe hypersensitivity to oral CAIs were excluded.

This study was approved and authorized by the Ethics Committee of the University of Ryukyus Faculty of Medicine and conducted according to the tenets of the Declaration of Helsinki. Written informed consent was obtained from all patients prior to study commencement.

\section{Methods}

Eligible patients were randomized by two-group crossover method to receive either dorzolamide $1 \%$ or brinzolamide $1 \%$ (the available formulations in Japan) eye drops twice daily (at 09:00 and 21:00) in combination with latanoprost (given once daily at 21:00) for 4 weeks. At the end of four weeks, they were hospitalized as follows. In the brinzolamide group, patients continued to receive the same combination therapy while their IOP was measured by physician specializing in glaucoma using Goldmann applanation tonometer every three hours from 09:00 till 24:00 and at 06:00 and 9:00 the next day. Whereas, in the dorzolamide group the patients underwent the same 24-hour IOP observation as in the brinzolamide group on two consecutive days: at first while continuing to receive dorzolamide twice daily then over the next 24 hours while receiving dorzolamide thrice daily (given at 09:00, 15:00, and 21:00). The patients in the two drug treatment groups were then crossed over to receive the other test medication for another four weeks followed by measurement of 24-hour IOP as before.

IOP was analyzed in one eye/patient. If both eyes were eligible for inclusion that with higher IOP was selected as the study eye; when IOP was the same in both eyes the right eye was selected. IOP measurements were conducted in duplicate at each time point, with the higher measurement adopted and verified by the investigators.

All patients underwent thorough ophthalmic evaluations before and at each visit during the study. Subjective ocular discomfort and adverse events and their duration after instillation of eye drops were investigated by patient interviews. Patients who complained of irritation and/or blurred vision at least once during the experimental period were regarded as having ocular discomfort. At the end of the study, the patients were asked to express any preference for dorzolamide or brinzolamide.

\section{Statistical analysis}

Data are expressed as mean \pm standard deviation (SD). Intragroup differences between baseline and on-treatment IOP were analyzed by multiple comparison method after repeated measures analysis of variance (ANOVA). Percent IOP reduction in daytime and nighttime and area under the curve (AUC) of 24-hour IOP were compared among treatment groups by ANOVA with ad hoc multiple comparison method. AUC was squared in each trapezoid. Patient survey results were compared by Fisher's exact test. All statistical tests were performed with $\alpha=0.05$ at two-tailed and with $80 \%$ power $(1-\beta)$. 
$P$-values $<0.05$ were considered statistically significant. All statistical analyses were performed using STATISTICA version 06J (StatSoft Japan Inc, Tokyo, Japan).

\section{Results}

This study involved 20 Japanese patients (M/F, 11/9; mean age, $65.7 \pm 10.2$ years). Eleven patients had POAG, three $\mathrm{OH}$, and six ACG. All ACG patients had been treated with LI $>3$ months before enrolment in this study. Although all 20 patients in the dorzolamide bid and brinzolamide bid groups underwent 24-hour assessment of IOP, only 17 patients did so in the dorzolamide tid group; the reason for dropping out was personal choice (not because of side effects) in all three cases.

Mean baseline IOP was $20.0 \pm 1.4 \mathrm{mmHg}$. After four weeks of treatment and during hospital stay, mean IOP values on both drugs in combination with latanoprost were significantly $(p<0.001)$ reduced from baseline at all time-points throughout the 24-hour period as shown in Table 1 and Figure 1.

Percent reduction of IOP from baseline on dorzolamide bid and tid and brinzolamide bid was $17.3 \pm 10.0 \%$, $21.0 \pm 9.4 \%$, and $17.8 \pm 8.8 \%$, respectively, during daytime and $21.1 \pm 9.5 \%, 20.5 \pm 10.2 \%$, and $18.5 \pm 11.7 \%$, respectively, at night (Table 2 and Figure 2). No significant difference was noted among the three groups. AUC of IOP reduction over 24 hours in the three treatment groups was $385 \pm 39,381 \pm 39$, and $394 \pm 47 \mathrm{mmHg} \cdot$ hour, respectively.

Ocular discomfort/adverse events during the treatment period were mild eye irritation $(n=8)$, mild foreign body sensation $(n=1)$, and mild blurred vision $(n=3)$ in patients receiving dorzolamide and mild eye irritation $(n=4)$, mild foreign body sensation $(n=2)$, and blurred vision ( $\mathrm{n}=12$; severe in 2 patients and mild in 10 patients) in those receiving brinzolamide (Figure 3). According to the patients' questionnaire survey conducted at end of study, significantly $(P<0.05)$ more patients favored dorzolamide $1 \%(\mathrm{n}=9)$ than brinzolamide $1 \%(\mathrm{n}=2)$, whereas nine patients did not express any preference for either drug. The major reported reasons for preference of dorzolamide over brinzolamide were that brinzolamide left white residue on eye lashes and caused long-lasting blurred vision including severe blurring in two cases.

\section{Discussion}

In the present study dorzolamide $1 \%$ applied twice or thrice daily and brinzolamide $1 \%$ twice daily exerted significant 24-hour IOP-lowering activity when added to latanoprost in Japanese patients with POAG, OH, and ACG. The 24-hour IOP-lowering efficacy of each CAI as second-line medication in combination therapy with latanoprost appeared similar, as did that of the twice- and thrice-daily dosing schedules of dorzolamide. However, patients' preference significantly favored dorzolamide over brinzolamide mainly because of whitish precipitate and blurred vision of long duration associated with instillation of the latter eye drops; irritation was not a significant factor in this result.

In a previous study looking at IOP reduction, brinzolamide $1 \%$ exerted equivalent efficacy to dorzolamide $2 \%$ when added to timolol $0.5 \%$ in patients with $\mathrm{POAG}$ and $\mathrm{OH} .{ }^{21}$ Moreover, when added to latanoprost in patients with glaucoma and $\mathrm{OH}$, dorzolamide $2 \%$ decreased IOP by $3.9 \mathrm{mmHg}$ $(19.7 \%) .{ }^{17}$ Whereas, addition of brinzolamide to latanoprost reduced IOP by $5.2 \mathrm{mmHg}(24.6 \%)$ in patients with POAG or $\mathrm{OH} .{ }^{18} \mathrm{IOP}$ was maintained without further decrease when brinzolamide $1 \%$ was substituted for dorzolamide $1 \%$ in combination therapy with latanoprost and timolol. ${ }^{22,23}$ The present study demonstrated almost identical effect on IOP reduction when the two CAIs examined were added to latanoprost.

This study included 11 subjects with POAG, three with $\mathrm{OH}$, and six with ACG. Although there are clear differences in the underlying causes of hyper-IOP between POAG and ACG, the IOP-lowering mechanism and effect of topical antiglaucoma agents including CAIs is considered common among the patients who were included in this study. Regardless, to assess whether there were any differences of efficacy between brinzolamide and dorzolamide among the different patient groups, we performed a stratified analysis and found that in 11 POAG patients reduction of daytime IOP was $-3.5 \pm 2.5 \mathrm{mmHg}$ by dorzolamide bid, $-4.6 \pm 2.5 \mathrm{mmHg}$ by dorzolamide tid,

Table I Time-course of intraocular pressure (IOP; mean \pm SD) during overnight hospital stay in three treatment groups

\begin{tabular}{|c|c|c|c|c|c|c|c|c|c|}
\hline & \multicolumn{9}{|c|}{ IOP, mmHg } \\
\hline & Baseline & 09:00 & I2:00 & $15: 00$ & $18: 00$ & $21: 00$ & $24: 00$ & $06: 00$ & 09:00 \\
\hline Dorzolamide bid & $20.0 \pm 1.4$ & $17.3 \pm 2.6$ & $15.7 \pm 2.6$ & $16.5 \pm 1.7$ & $16.6 \pm 2.4$ & $15.7 \pm 1.6$ & $15.9 \pm 2.0$ & $15.9 \pm 2.5$ & $15.5+1.4$ \\
\hline Dorzolamide tid & $20.0 \pm 1.5$ & $15.5 \pm 2.7$ & $15.2 \pm 2.0$ & $15.6 \pm 2.1$ & $16.6 \pm 2.1$ & $15.7 \pm 2.3$ & $16.5 \pm 2.0$ & $15.8 \pm 2.0$ & $15.3 \pm 1.4$ \\
\hline Brinzolamide bid & $20.0 \pm 1.4$ & $16.8 \pm 2.9$ & $16.2 \pm 2.0$ & $16.1 \pm 1.9$ & $16.7 \pm 2.0$ & $15.9 \pm 2.8$ & $16.9 \pm 3.3$ & $16.6 \pm 3.3$ & $15.8+1.4$ \\
\hline
\end{tabular}




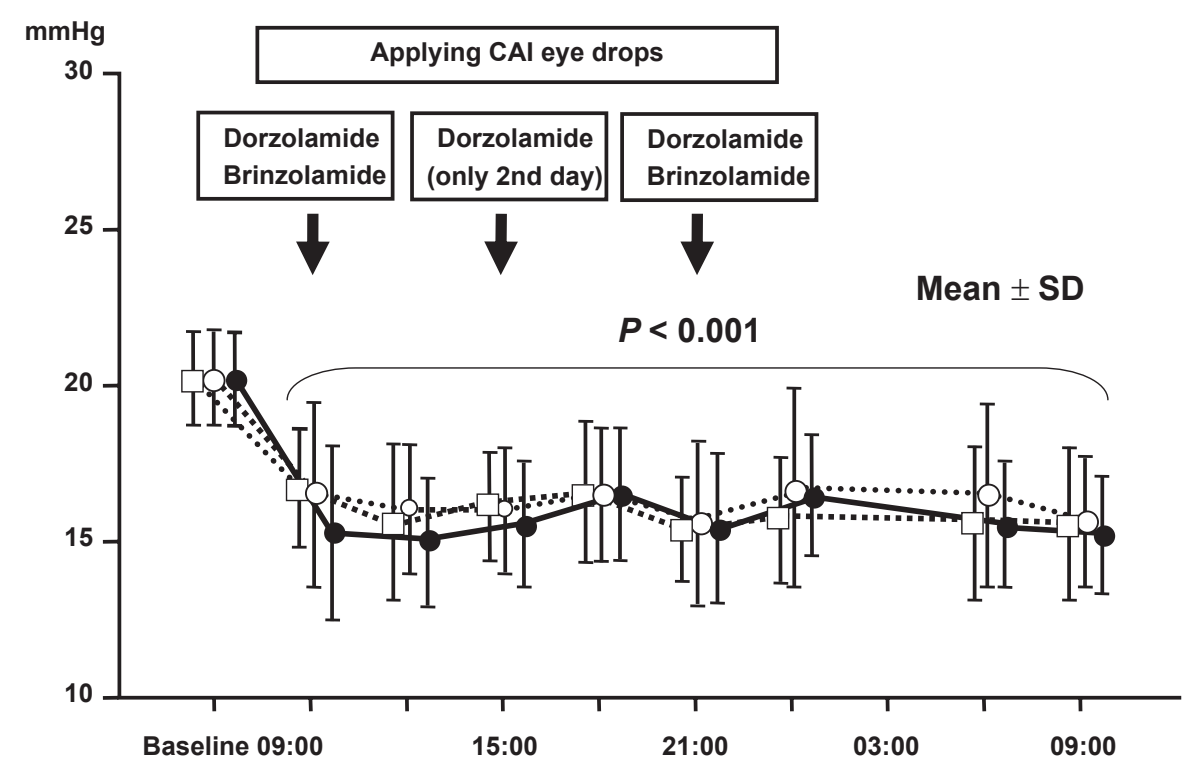

Figure I Twenty-four-hour change of intraocular pressure (IOP) in the three treatment groups.

Notes: $\square$, Dorzolamide bid $(n=20)$; O, brinzolamide bid $(n=20)$;, dorzolamide tid $(n=17)$. Significant reduction of IOP from baseline was noted in all 3 treatment groups at all measurement time-points (paired $t$-test).

and $-3.6 \pm 2.3 \mathrm{mmHg}$ by brinzolamide bid; in six ACG patients the results were $-2.8 \pm 1.7 \mathrm{mmHg},-3.6 \pm 1.4 \mathrm{mmHg}$, and $3.7 \pm 1.4 \mathrm{mmHg}$, respectively. No significant difference was noted between POAG and ACG patients on any of the test regimens. Moreover, the results of nighttime IOP were similar to those obtained during daytime (data not shown). Therefore CAI efficacy seems common in various glaucoma patients with hyper-IOP.

Several previous studies have reported that dorzolamide ( $1 \%$ and $2 \%$ ) is associated with burning sensation or irritation because of its acidic formulation ( $\mathrm{pH}, 5.6)$. Brinzolamide, on the other hand, often induces blurred vision due to its insoluble carboxyvinyl polymer. As was expected, similar results were noted in the present study: eight patients reported eye irritation while on dorzolamide and 12 patients reported blurred vision on brinzolamide. These symptoms were transient and faded without treatment.

We recorded that nine patients preferred dorzolamide and two preferred brinzolamide whereas nine gave a neutral answer. Compliance is a key issue in the treatment of glaucoma; patients are thought more likely to adhere to a course of therapy that is well tolerated. In an earlier prospective, multicenter, double-blind, parallel group trial ${ }^{24}$ although blurred vision occurred in $20 \%-25 \%$ of subjects who took brinzolamide, this medication was assessed as significantly more comfortable than dorzolamide $2 \%$. In that study, the concentration of dorzolamide was twice as high as the $1 \%$ solution examined in this study. Other researchers have reported that substituting brinzolamide $1 \%$ for dorzolamide $1 \%$ in Japanese patients with POAG maintained stable IOP while improving ocular comfort without significant increase of blurred vision. ${ }^{22,23}$

In the domestic phase IIb study of dorzolamide, ${ }^{25}$ no significant difference of efficacy was observed between $1 \%$ and $2 \%$ solutions whereas the latter concentration was associated with more adverse reactions. These results influenced the Japanese regulatory authority to approve dorzolamide $0.5 \%$ and $1 \%$ for clinical use. In the present study we observed that patients who received dorzolamide $1 \%$ experienced little ocular discomfort and significantly preferred dorzolamide $1 \%$ over brinzolamide $1 \%$.

In conclusion, administration of CAIs concomitantly with latanoprost elicited significant further reductions of 24-hour IOP. The IOP-lowering efficacy was almost identical regardless of whether patients received dorzolamide

Table 2 Reduction of 24-hour and daytime/nighttime intraocular pressure (mean $\pm \mathrm{SD}$ ) in three treatment groups

\begin{tabular}{|c|c|c|c|}
\hline & $\begin{array}{l}\text { Dorzolamide } \\
\text { bid }\end{array}$ & $\begin{array}{l}\text { Dorzolamide } \\
\text { tid }\end{array}$ & $\begin{array}{l}\text { Brinzolamide } \\
\text { bid }\end{array}$ \\
\hline Baseline, $\mathrm{mmHg}$ & $20.0 \pm 1.4$ & $20.0 \pm 1.5$ & $20.0 \pm 1.4$ \\
\hline \multicolumn{4}{|l|}{ Week $12, \mathrm{mmHg}$} \\
\hline 24 hour & $16.1 \pm 1.6$ & $15.8 \pm 1.6$ & $16.4 \pm 1.9$ \\
\hline Daytime & $16.5 \pm 1.9$ & $15.8 \pm 1.8$ & $16.4 \pm 1.8$ \\
\hline Nighttime & $15.8 \pm 1.8$ & $15.8 \pm 1.6$ & $16.4 \pm 2.4$ \\
\hline
\end{tabular}

Notes: Daytime, 09:00-18:00; nighttime, 21:00-09:00. 
Daytime (09:00-18:00)

Dorzolamide Brinzolamide Dorzolamide

bid

(n=20)

bid

(n = 20)

tid

(n=17)

$\left.\begin{array}{r}0 \\ -10 \\ -20 \\ -30 \\ -40 \\ -50\end{array}\right]$

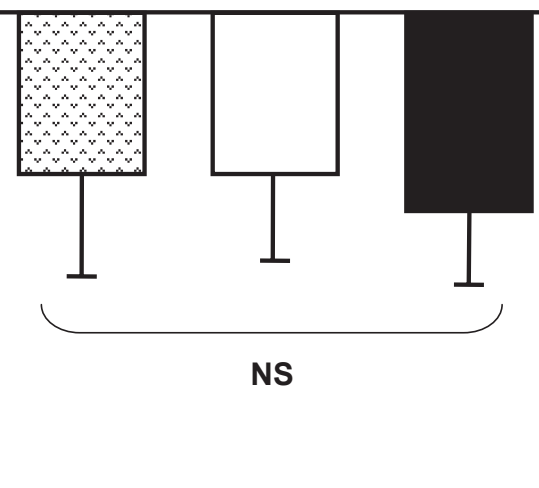

Nighttime (21:00-09:00)

Dorzolamide Brinzolamide Dorzolamide

bid

bid

tid

( $n=20)$

( $n=20)$

( $n=17)$

(\%)

Figure 2 Percent additional intraocular pressure (IOP) reduction during the day and at night. No significant difference of daytime and nighttime mean percent additional IOP reduction was noted among the three treatment groups as determined by analysis of variance.

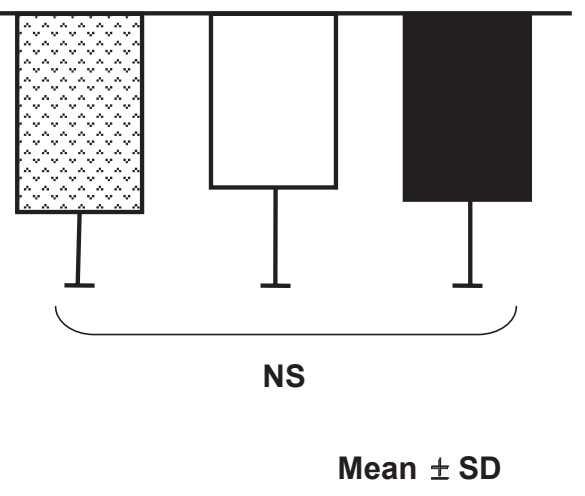

Mean \pm SD

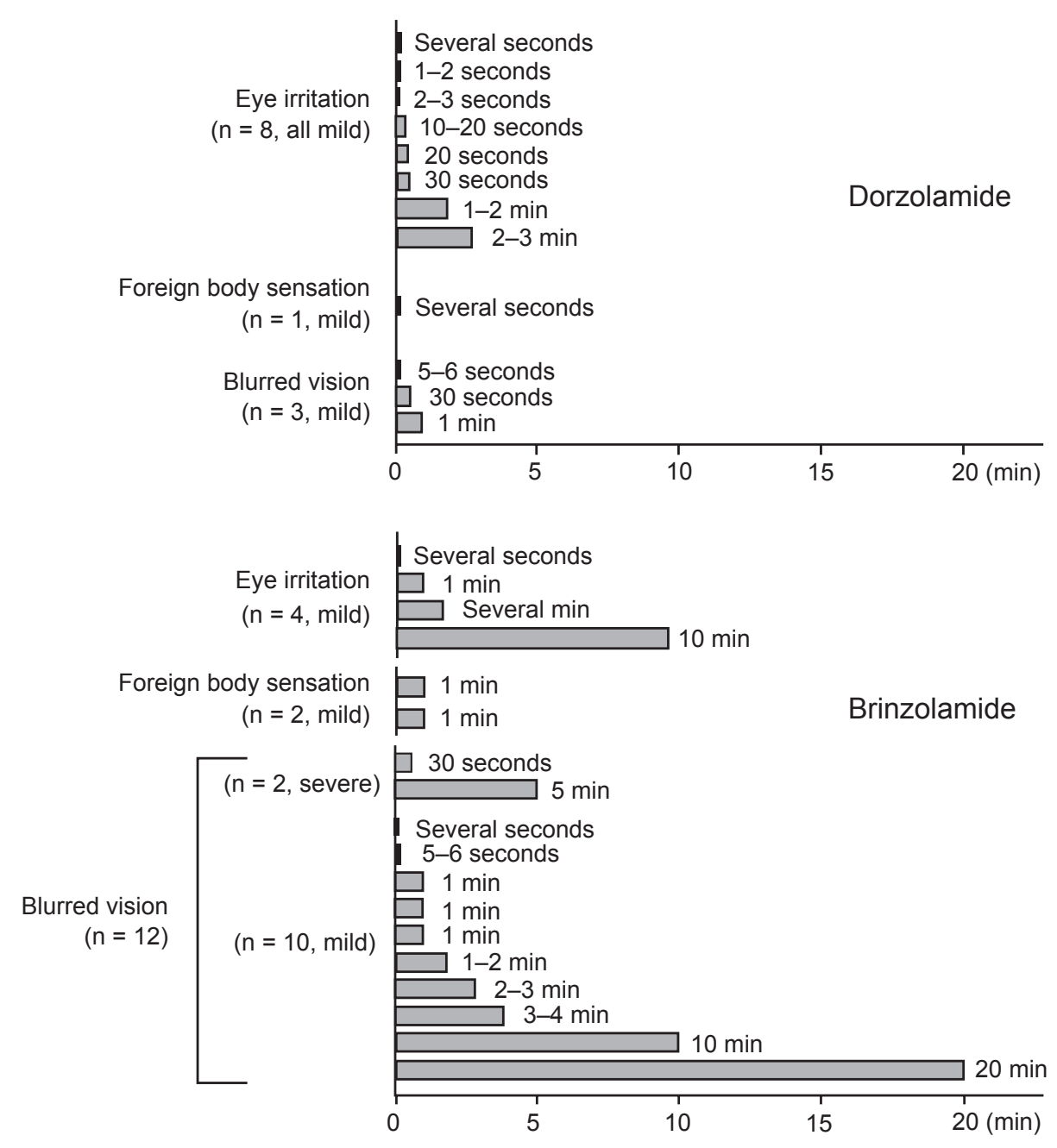

Figure 3 Ocular discomfort and adverse events and their duration under treatment with each carbonic anhydrase inhibitor. 
$1 \%$ bid or tid or brinzolamide $1 \%$ bid in combination with latanoprost. However, dorzolamide $1 \%$ was significantly preferred over brinzolamide $1 \%$ in our cohort of Japanese patients with glaucoma.

\section{Disclosure}

The authors have no conflict of interest to declare.

\section{References}

1. Sommer A, Tielsch JM, Katz J, et al. Relationship between intraocular pressure and primary open angle glaucoma among white and black Americans. The Baltimore Eye Survey. Arch Ophthalmol. 1991;109:1090-1095.

2. Kass MA, Heuer DK, Higginbotham EJ, et al. The Ocular Hypertension Treatment Study. A randomized trial determines that topical hypotensive medication delays or prevents the onset of primary-open angle glaucoma. Arch Ophthalmol. 2002;120:701-713.

3. Gaasterland DE, Ederer F, Beck A, et al. The Advanced Glaucoma Intervention Study (AGIS): the relationship between control of intraocular pressure and visual field deterioration. Am J Ophthalmol. 2000;130:429-440.

4. Lichter PR, Musch DC, Gillespie BW, et al. CIGTS Study Group: interim clinical outcomes in the Collaborative Initial Glaucoma Treatment Study comparing initial treatment randomized to medications or surgery. Ophthalmology. 2001;108:1943-1953.

5. Japan Glaucoma Society. Guidelines for glaucoma 2004. Accessed on Jan 10, 2009. Available from: http://www.ryokunaisho.jp/.

6. Alward WL. Medical management of glaucoma. $N$ Engl J Med. 1998;339:1298-1307.

7. Kobelt-Nguyen G, Gerdtham UG, Alm A, et al. Costs of treating primary open-angle glaucoma and ocular hypertension: a retrospective, observational chart review of newly diagnosed patients in Sweden and the United States. J Glaucoma. 1998;7:95-104.

8. Camras CB, Alm A, Watson P, et al. Latanoprost, a prostaglandin analog, for glaucoma therapy: efficacy and safety after 1 year of treatment in 198 patients. Latanoprost Study Groups. Ophthalmology. 1996;103:1916-1924.

9. Silver LH. Clinical efficacy and safety of brinzolamide (Azopt), a new topical carbonic anhydrase inhibitor for primary open-angle glaucoma and ocular hypertension. Brinzolamide Primary Therapy Study Group. Am J Ophhthalmol. 1998;126:400-408.

10. Brubaker RF, Ingnam CJ, Schoff EO, et al. Comparison of the efficacy of betaxalol-brinzolamide and timolol-dorzolamide as suppressors of aqueous humor flow in human subjects. Ophthalmology. 2000; $107: 283-287$.

11. Alm A, Stjernschantz J. Effects on intraocular pressure and side effects of $0.005 \%$ latanoprost applied once daily, evening or morning: a comparison with timolol. Scandinavian Latanoprost Study Group. Ophthalmology. 1995;102:1743-1752.

12. Camras CB. Comparison of latanoprost and timolol in patients with ocular hypertension and glaucoma: a six month masked, multicenter trial in the United States. The United States Latanoprost Study Group. Ophthalmology. 1996;103:138-147.

Clinical Ophthalmology

\section{Publish your work in this journal}

Clinical Ophthalmology is an international, peer-reviewed journal covering all subspecialties within ophthalmology. Key topics include: Optometry; Visual science; Pharmacology and drug therapy in eye diseases; Basic Sciences; Primary and Secondary eye care; Patient Safety and Quality of Care Improvements. This journal is indexed on Submit your manuscript here: http://www.dovepress.com/clinical-ophthalmology-journal
13. Mishima HK, Masuda K, Kitazawa Y, et al. A comparison of latanoprost and timolol in primary open angle glaucoma and ocular hypertension. A 12 week study. Arch Ophthalmol. 1996;114:929-932.

14. Watson P, Stjernschantz J. A six month, randomized, double masked study comparing latanoprost with timolol in open angle glaucoma and ocular hypertension. The Latanoprost Study Group. Ophthalmology. 1996;103:126-137.

15. Alm A, Widengard I, Kjellgren D, et al. Latanoprost administrated once daily caused a maintained reduction of intraocular pressure in glaucoma patients treated concomitantly with timolol. Br JOphthalmol. 1995;79:12-16.

16. Higginbotham EJ, Feldman R, Stiles M, et al. Fixed Combination Investigative Study Group. Latanoprost and timolol combination therapy vs monotherapy: one-year randomized trial. Arch Ophthalmol. 2002;120:915-922.

17. O'Connor DJ, Martone JF, Mead A. Additive intraocular pressure lowering effect of various medications with latanoprost. Am J Ophthalmol. 2002;133:836-837.

18. Shoji N, Ogata H, Suyama H, et al. Intraocular pressure lowering effect of brinzolamide $1 \%$ as adjunctive therapy to latanoprost $0.005 \%$ in patients with open angle glaucoma or ocular hypertension: an uncontrolled, open-label study. Curr Med Res Opin. 2005;21:503-507.

19. Ishikawa S, Nakamura Y, Nakamura Y, et al. Efficacy and safety of combination therapy with latanoprost after a change in therapeutic regimen from timolol to brinzolamide in Japanese adult patients with primary open-angle glaucoma and ocular hypertension: open, nonrandomized 12 week study. Clin Ophthalmol. 2008;2:703-708.

20. Tamer C, Oksuz H. Circadian intraocular pressure control with dorzolamide versus timolol maleate add-on treatments in primary open-angle glaucoma patients using latanoprost. Ophthalmic Res. 2007;39:24-31.

21. Michaud JE, Friren B; International Brinzolamide Adjunctive Study Group. Comparison of topical brinzolamide $1 \%$ and dorzolamide $2 \%$ eye drops given twice daily in addition to timolol $0.5 \%$ in patients with primary open-angle glaucoma or ocular hypertension. Am JOphthalmol. 2001;132:235-243.

22. Tsukamoto H, Noma H, Matsuyama S, et al. The efficacy and safety of topical brinzolamide and dorzolamide when added to the combination therapy of latanoprost and a $\beta$-blocker in patients with glaucoma. J Ocular Pharmacol Ther. 2005;21:170-173.

23. Tsukamoto H, Noma H, Mukai S, et al. The efficacy and ocular discomfort of substituting brinzolamide for dorzolamide in combination therapy with latanoprost, timolol, and dorzolamide. J Ocular Pharmcol Ther. 2005;21:395-399.

24. Silver LH. Ocular comfort of brinzolamide $1.0 \%$ ophthalmic suspension compared with dorzolamide $2.0 \%$ ophthalmic solution: results from two multicenter comfort studies. The Brinzolamide Comfort Study Group. Surv Ophthalmol. 2000;44:S141-S145.

25. Kitazawa Y, Azuma I, Iwata K, et al. Dorzolamide, a topical carbonic anhydrase inhibitor: A two-week dose-response study in patients with glaucoma or ocular hypertension. J Glaucoma. 1994;3:275-279.

\section{Dovepress}

PubMed Central and CAS, and is the official journal of The Society of Clinical Ophthalmology (SCO). The manuscript management system is completely online and includes a very quick and fair peer-review system, which is all easy to use. Visit http://www.dovepress.com/ testimonials.php to read real quotes from published authors. 